\title{
CALCIUM METABOLISM IN IDIOPATHIC HYPER- CALCAEMIA OF INFANCY WITH FAILURE TO THRIVE
}

\author{
BY \\ R. E. BONHAM CARTER, C. E. DENT, DOROTHY I. FOWLER \\ and CHRISTINE M. HARPER \\ From University College Hospital and Medical School, London
}

(RECEIVED FOR PUBLICATKON JUNE 5, 1955)

As pointed out by a leader in the Lancet (1953), marasmus or 'teething' no longer satisfies paediatricians as a diagnosis for an infant's failure to thrive. The clinical studies of Lightwood and the biochemical work of Payne have recently shown that failure to thrive with constipation, hypotonia, polyuria, loss of appetite with occasional vomiting and intermittent urinary infection may be associated with at least two biochemical patterns, the first being that of renal acidosis (Lightwood, Payne and Black, 1953) and the second that of hypercalcaemia (Lightwood, 1952). Although the biochemical findings have now enabled these disease patterns to be identified from the ruck of marasmus and have led to hopeful therapeutic attempts to correct the biochemical abnormalities, the aetiology of both conditions remains in doubt.

The hypercalcaemic syndrome has apparently two forms, a commoner and milder form (Lightwood, 1952; Creery and Neill, 1954; Lowe, Henderson, Park and McGreal, 1954) and a more severe form (Fanconi, Girardet, Schlesinger, Butler and Black, 1952; Lowe et al., 1954). The milder form has been attributed by Creery and Neill (1954) and others to excessive vitamin D or calcium intake and by Lowe et al. (1954) to hypersensitivity to vitamin D. Some evidence that individual differences occur in sensitivity to the toxic action of vitamin $D$ has been summarized by Bicknell and Prescott (1942). The possibility, therefore, that either or both forms of hypercalcaemia are due not so much to an excessive intake but to an innate or induced sensitivity to vitamin $\mathbf{D}$ must also be considered.

In the hypercalcaemic syndrome an additional feature in some cases has been a systolic murmur which Bonham Carter, after investigating Lightwood's cases, has suggested might be associated with the hypertension and atheroma which accompanies this condition in some of its phases (unpublished observations). This was the immediate reason for the referral of the case described below.
In the present paper we describe metabolic studies on an infant with the milder form of the hypercalcaemic syndrome. We were especially concerned to investigate whether there is indeed an excessive sensitivity to vitamin $D$ in this disease, also how far the metabolic abnormalities mimic an overdose of the vitamin and, finally, how far the symptoms might be due to the hypercalcaemia and might therefore respond to measures aimed at correcting this abnormality.

\section{Case History}

The child (Peter M.) was referred by Dr. Ellis of Romford to the Children's Department of University College Hospital because of failure to thrive with vomiting and a cough; he had observed a systolic murmur maximal in the pulmonary areas. The child was admitted to the children's ward on October 13, 1952. He was 9 months old and his history was of loss of weight for six weeks, with loss of appetite and vomiting between meals for the same period. The illness started with a cough, but his parents noticed that he had been flabby for seven weeks before this. His earlier history was uneventful. His birth weight was $7 \mathrm{lb} .8 \mathrm{oz}$. following a normal pregnancy and labour. He was breast fed for three months and then he was given 'ostermilk' and mixed feeding at $4 \frac{1}{2}-5$ months. His development was normal up to the time of his illness. Constipation was only slight and there was no evidence of an abnormally high intake of vitamin D.

The child was wasted and hypotonic but not dehydrated. The only other physical sign found was a systolic murmur, maximal in the pulmonary area. Investigations at that time showed haemoglobin $82 \%$, W.B.C. 18,000 , E.S.R. $45 \mathrm{~mm}$./hr. The urine contained $0 \cdot 1$ parts per 1,000 of protein with numerous pus cells and gave a growth of Proteus vulgaris. There was tryptic activity in the stool. Radiographs showed some peribronchial changes in the lung fields, but no evidence of rickets. The bones were well calcified and of normal structure. The blood urea was $24 \mathrm{mg}$./100 ml.; calcium $13.8 \mathrm{mg}$./100 ml.; phosphatase 7.5 units (King-Armstrong). Total protein was $6.85 \mathrm{~g} . / 100 \mathrm{ml}$; bicarbonate $26 \mathrm{mEq} . / \mathrm{l}$; chlorides 
$102 \mathrm{mEq} . / 1$. These biochemical investigations led to a diagnosis of idiopathic hypercalcaemia.

From admission on October 13, 1952, until the beginning of December, the child remained in rather poor condition, but gained weight slowly from $6 \cdot 25$ to about $7 \cdot 5 \mathrm{~kg}$. The urine contained pus cells most of the time and grew at various times Proteus vulgaris, Staph. albus, and a mixed flora, being also sterile on occasion. He had several febrile attacks which were treated with various antibiotics without much success (Fig. 1). At

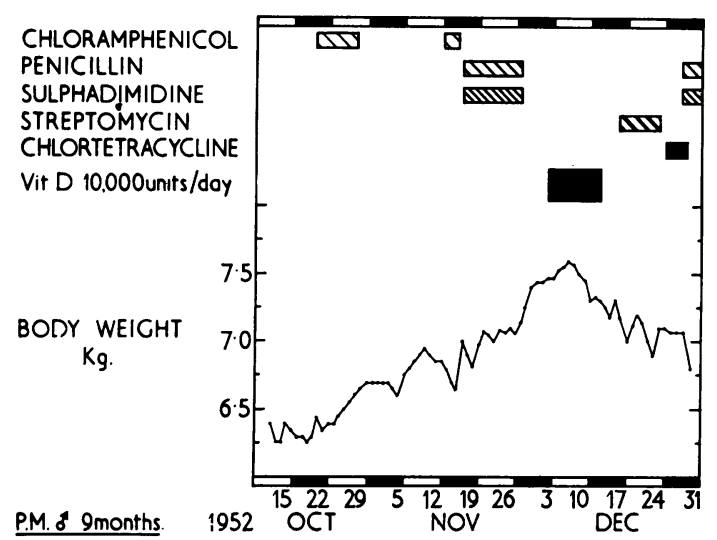

Fig. 1.-Weight curve while in the children's ward. It is noted that definite loss of weight followed 10 days on 10,000 units a day of vitamin $D$ as calciferol. The use of antibiotic treatment is also shown as an indication of the child's repeated infections.

this time we began to suspect that vitamin D sensitivity was the cause of his disease. Because, therefore, of the lack of any definite improvement and doubts as to the future management of such a case, it was considered justifiable to administer a provocative small dose of vitamin $\mathrm{D}$, which would settle once and for all whether he was sensitive to it and whether rigorous omission of it from the diet was a necessary part of his treatment. Therefore on December 1, 1952, he was given vitamin D, 10,000 units a day by mouth in the form of $\frac{1}{4} \mathrm{mg}$. a day of pure calciferol. The plasma calcium level had been 10.6 on November 21. On December 9 it had risen to 11.2. The results became known on December 12, and as his condition was beginning to deteriorate, vitamin D was stopped. The plasma calcium on December 13 was $11.9 \mathrm{mg} . / 100 \mathrm{ml}$.

He had not shown any marked clinical changes during the 12 days when calciferol was given. However, soon after this his condition did appear to worsen markedly and a loss of weight became obvious (Fig. 1). This continued till by the end of December his body weight had fallen to $7.0 \mathrm{~kg}$.; he was much more difficult to feed and he had become very miserable and hypotonic. Unfortunately no further serum calcium levels were determined during this period. We presume that they were raised as the next reading on January 4 was 11.4 $\mathrm{mg} . / 100 \mathrm{ml}$. Blood urea had been normal at $21 \mathrm{mg}$. \% at the end of vitamin D administration on December 13; it rose to $30 \mathrm{mg}$. on December 19 and was still the same on the 30th. It was in this poor condition that he was transferred on January 1, 1953, to the metabolic ward.

In the metabolic ward a diet was arranged for him which contained 1,000 calories a day and included $500 \mathrm{ml}$. of milk, and was complete in salts and vitamins except that no vitamin D was added. This diet contained 610 mg. of calcium and was practically free from vitamin $D$. It was given in exactly measured quantities until February 27, 1953. However, at the intervals stated below, the milk was treated with ion exchange resin to exchange all the calcium (and other polyvalent metals) for sodium and potassium. Details of the diet are shown in Table 1.

\section{TABLE 1}

DIET GIVEN WHILE IN METABOLIC WARD

$500 \mathrm{ml}$. milk (ordinary homogenized or decalcified, according to
schedule described later)
$250 \mathrm{ml}$. of high calorie supplement comprising:
$100 \mathrm{~g}$. glucose
$22 \mathrm{~g}$. (25 ml.) arachis oil
$6.25 \mathrm{~g}$. gum acacia
distilled water up to $250 \mathrm{ml}$. and the
whole shaken till apparently homogeneous
$250 \mathrm{ml}$. distilled water containing:
$5 \mathrm{mg}$. aneurin
$5 \mathrm{mg}$. ribotiavine
$50 \mathrm{mg}$. nicotinamide
$50 \mathrm{mg}$. ascorbic acid
$5 \mathrm{mg}$. pyridoxine
$10 \mu \mathrm{g}$. vitamin $\mathrm{B}_{1}^{1}$
$0.1 \mathrm{ml}$. colliron $(10 \%$ strength)

The daily diet above measured 11 and was given as five feeds of $200 \mathrm{ml}$. each. When the calcium-free diet was given (by using decalcified milk instead of ordinary milk), a supplement of $0.5 \mathrm{~g}$. magnesium sulphate and $3 \mathrm{~g}$. potassium chloride was made. The decalcified milk was prepared as described by Dent (1955).

On January 2 the calcium-free form of the diet was given (Fig. 2); on the 10th the calcium-containing form; on the 17th the calcium-free; on the 24 th the calciumcontaining; on February 7 the calcium-free; on the 21 st the calcium-containing; on the 26th the calcium-free. By February 27 it was considered that adequate information had been obtained as to the effect of this quantity of calcium in the diet, so a new diet comprising more mixed food but limited to a daily intake of $200 \mathrm{mg}$. of calcium was given. This was an attempt to devise a diet suitable for taking at home. However, the calcium content appeared to be still too high, so it was limited to $100 \mathrm{mg}$. a day on March 15 and two days later raised to $200 \mathrm{mg}$. with an addition of $50 \mathrm{~g}$. of 'all-bran' as a source of phytic acid. On this the child worsened and the calcium-free diet was begun again on March 22, 1953. After the clinical and biochemical improvement thus obtained a further attempt was made on April 8 to keep him on a mixed diet limited to $200 \mathrm{mg}$. of calcium, but with $50 \mathrm{~g}$. of 'all-bran' a day. He continued on this until he went home on May 20, 1953.

While on these diets, repeated determinations of plasma calcium, phosphorus and urea were made and also daily body weighings and routine urine examinations. Calcium balance determinations were also done on four occasions during four-day collection periods, and further 


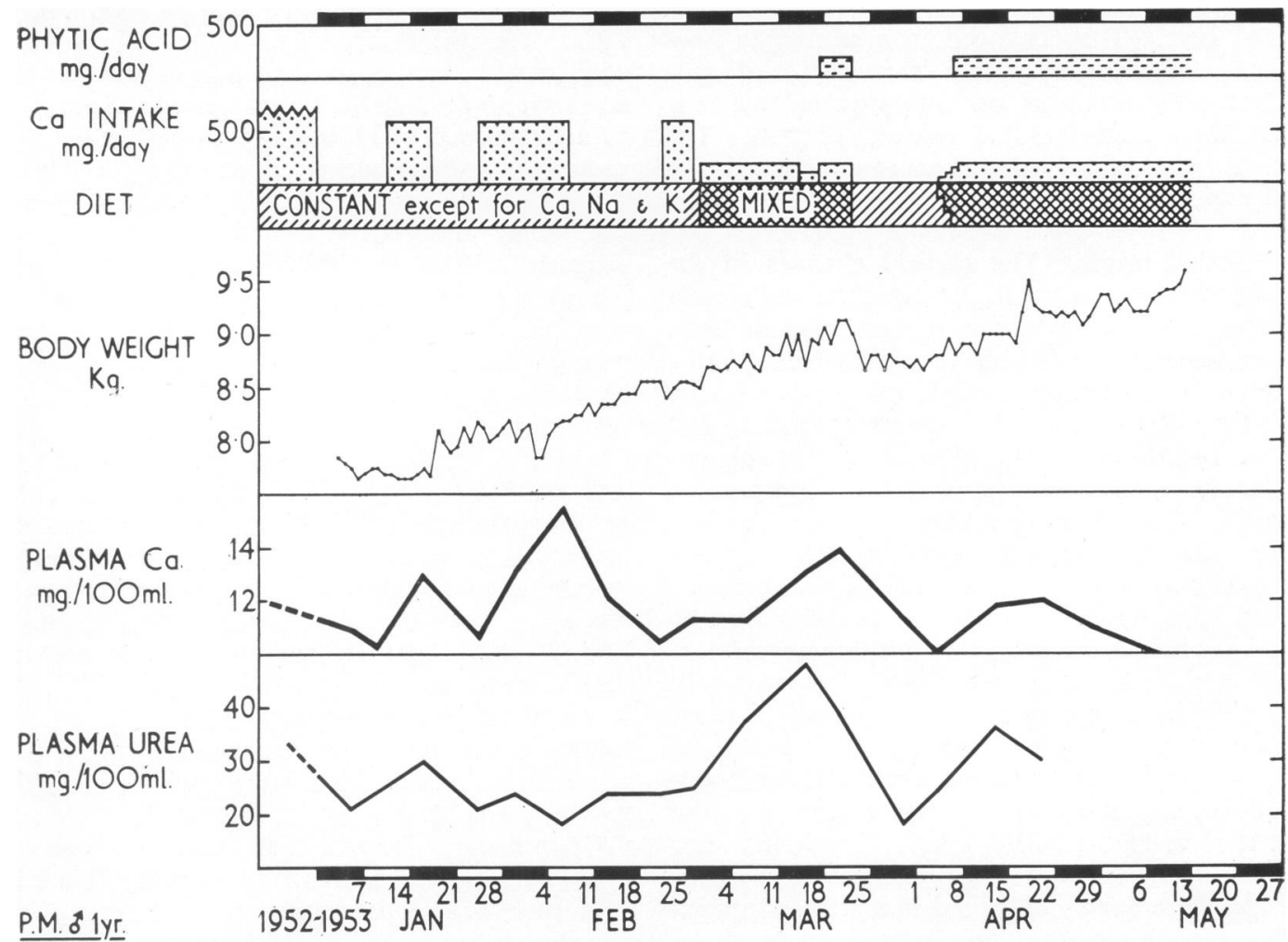

FIG. 2.-The extreme lability of the plasma calcium level should be noted. It rose rapidly whenever calcium was introduced into the diet. There is an embarrassing jump of body weight between periods shown in Fig. 1 and in this figure. This corresponds to some rehydration but we think it was mainly due to a change in the scales used in the two wards. We unfortunately omitted to investigate this at the time.

occasional 24-hour urine collections were also made for analysis of total calcium. During most of his time he was taking by mouth sulphadimidine, $0 \cdot 25 \mathrm{~g}$. b.d., as a prophylactic.

\section{Methods}

For collection of specimens of urine and faeces for the balance determinations the procedure of Black (1951) was followed.

Standard laboratory methods were used for the determinations of calcium (Clark and Collip, 1925), phosphorus and urea.

\section{Results}

Biochemical Changes and their Interpretation. The main results are summarized in the chart shown in Fig. 2. This shows clearly that the calcium-free diet readily reduced the plasma calcium levels to normal while the calcium-containing diet caused it to rise quickly to grossly abnormal levels. Plasma urea tended to rise and fall with the calcium level, but on the whole there was a gradual fall throughout the period on the standardized diet. There was a large rise in plasma urea when mixed feeding was begun.
We presume that this was due to an increased protein intake since the intake was rather low, only $20 \mathrm{~g}$. a day, on the standard diet. Clearly $200 \mathrm{mg}$. of calcium was too high an intake when first given, as the plasma calcium rose, and the addition of phytic acid for a few days did not appear to have much effect. When this diet was repeated later, however, it was tolerated by the patient, who showed this time only a small temporary rise in the plasma

TABLE 2

CALCIUM INTAKE AND OUTPUT FROM JANUARY TO APRIL, 1953

\begin{tabular}{l|cc|c|c}
\hline $\begin{array}{c}\text { Date } \\
\text { (inclusive) }\end{array}$ & $\begin{array}{c}\text { Urine Ca } \\
\text { (mg./day) }\end{array}$ & $\begin{array}{c}\text { Stool Ca } \\
\text { (mg./day) }\end{array}$ & $\begin{array}{c}\text { Diet Ca } \\
\text { (mg./day) }\end{array}$ & $\begin{array}{c}\text { Ca Balance } \\
\text { (mg./day) }\end{array}$ \\
\cline { 1 - 4 } Jan. 7-10 & 84 & 108 & 0 & -192 \\
Jan. 15 & 86 & & 610 & \\
Jan. 22 & 34 & & 0 & \\
Jan. 29-31 & 127 & & 610 & \\
Feb. 6 & 128 & & 610 & -126 \\
Feb. 12-15 & 41 & 85 & 0 & -126 \\
Feb. 19 & 42 & & 0 & +222 \\
Feb. 23-25 & 103 & 285 & 610 & +116 \\
Apr. 15-18 & 93 & 137 & 114 & -14 \\
\hline
\end{tabular}


calcium level. Plasma phosphorus levels are not quoted here. They changed in a seemingly haphazard manner, presumably because the dietary content of phosphorus was more variable in the mixed diets than was the calcium content. The calcium balance and urine calcium data are shown on Table 2.

Clinical Changes. The clinical changes in the patient were most interesting to observe and closely followed the changes in the plasma calcium level. On the calcium-free diet he got rapidly better, being more lively and taking his food much more easily. Each time he was given the calcium-containing diet (which invariably produced rises in the plasma calcium level) his condition worsened. He became more fretful and difficult to feed. He was also less active. On the second occasion the calciumcontaining diet was maintained for a fortnight instead of a week, as it seemed possible that he would become acclimatized to the higher calcium intake and that our previous result for one week may only have represented a temporary rebound phenomenon. The plasma calcium level continued to rise as fast during the second week on the calciumcontaining diet as during the first week, to reach the high level of $15.5 \mathrm{mg} . / 100 \mathrm{ml}$. A few hours after the child had been put back again on the calciumfree diet he suddenly collapsed in a state of apparently complete hypotonic paralysis, from which he recovered spontaneously after about 20 minutes. An electrocardiogram done soon after did not show changes suggestive of hypokalaemia so we interpreted this collapse as being due to the high plasma calcium level. At all events he rapidly improved in the next few days on a calcium-free diet. It appeared to us that during the course of this illness from the middle of February onwards he was becoming more tolerant of his dietary calcium. It was also of special note that several times during the course of the investigation, he had respiratory infections and febrile attacks whose cause was not always known. These complications only arose while he was taking calcium-containing diets. He was eventually sent home on May 20, 1953, the mother being advised to continue his diet containing about $200 \mathrm{mg}$. calcium with the high phytic acid content in the form of 'all-bran'. She was also advised to keep him out of the sun as much as possible to avoid the possibility of vitamin D synthesis on the skin.

\section{Follow-up of the Patient}

The child was seen at monthly intervals at first; later at three-monthly intervals. He remained on the 'all-bran' and low calcium intake until July 5, 1953. He was doing very well at this time and radiographs showed good growth of bone with no suggestion of rickets. His mother was then advised to add one cup of milk a day to his previous diet so as to raise his intake to about $\mathbf{4 0 0} \mathrm{mg}$. of calcium a day and she was told that from now on she need not worry about exposing him to the sun. On August 7, 1953, he showed further improvement. The plasma calcium level was $10 \cdot 6$, phosphorus $5 \cdot 5$, urea 36. He was told to eat any food he liked from now on with the one restriction that milk should be limited to two cups a day. From December 7, 1953, he was told to drink as much milk as he liked. Occasional attacks of bronchospasm had occurred and on February 20, 1954, he was admitted to St. Margaret's Hospital, Epping, with an attack of bronchitis and asthma. He responded well to ephedrine and sulphadimidine and went home on April 1, 1954. He was in excellent condition on May 31, 1954, appetite good, and his mother said that he was then drinking $1-1 \frac{3}{4}$ pints of milk a day. The plasma calcium level was $9 \cdot 9$, urea 42 . He continues well to the time of writing (April, 1955) when the plasma contained (mg./100 ml.) Ca, 10.3; P, 4.6; urea, 24.

Growth charts for weight and length are shown in Fig. 3. It can be seen when comparing his levels with the normal percentiles that he was grossly retarded around the age of 9 months, when this disease began, but that he made spectacular progress later and has now reached the 50 percentile levels of both weight and length. $\mathrm{He}$ is now very lively both physically and mentally, and appears well up to normal intelligence.

\section{Discussion}

We have described here the investigations and treatment of an infant who seems to fit very well the syndrome described by Lightwood (1952) as idiopathic hypercalcaemia of infancy with failure to thrive. The investigations seem to have shown clearly that this child was abnormally sensitive to vitamin $D$ since, when he was given 10,000 units a day as calciferol for 10 days in the beginning of December, 1952, he deteriorated rapidly and the plasma calcium and urea levels rose. This dose could have no such effect on a normal child, but in view of the known natural history of the disease it could still be argued that the change in the child's condition was spontaneous and not due to the vitamin $\mathbf{D}$ given. Investigations while he was in the metabolic ward showed the extraordinary lability of the plasma calcium level and its close dependence 
on changes in calcium intake. Clinical observations also showed a close correlation between his state of well-being and the plasma calcium level. At first sight this could be described as an intoxication by calcium since this was the only factor which varied throughout most of the investigation. The data suggest good absorption of calcium from the gut, although unfortunately it was not possible to perform good balance determinations in the earlier periods in which calcium was present in the diet
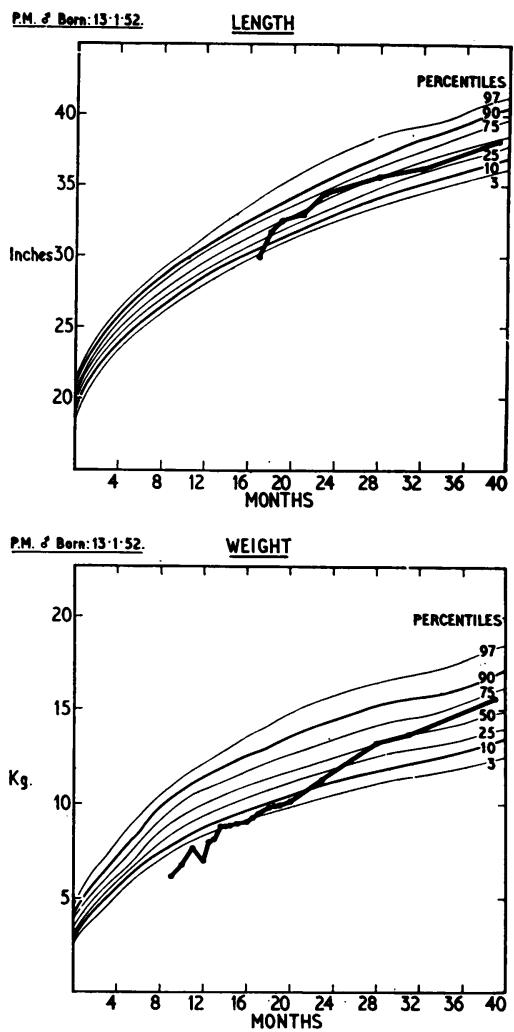

Fig. 3.-Growth and body weight curves during the illness and subsequent two-year follow-up.

owing to the child's poor condition. It can be presumed that there was good absorption from the gut at this time since it is difficult to see how otherwise the plasma calcium level could change so markedly and rapidly with changes only in the intake. This good absorption could be explained either as the continuing result on an exceptionally sensitive infant of the moderate doses of vitamin $\mathrm{D}$ given in early December, 1952, or in previous diet, or as due to the disease itself acting on some other still unknown mechanism. However, the former possibility seems more likely since the abnormality of calcium metabolism observed mimics so very closely an overdose of vitamin $D$ in the normal subject. We would stress here the low alkaline phosphatase level which is typically found in vitamin-D intoxication (Fanconi and de Chastonay, 1950) and was present in our infant; it has been reported without comment in some other cases of idiopathic hypercalcaemia. It is interesting to mention here the apparently identical disorder of calcium metabolism which occurs in some cases of sarcoidosis. There is good evidence that this also is due to an abnormal sensitivity to vitamin D (Anderson, Dent, Harper and Philpot, 1954; Henneman, Carroll and Dempsey, 1954). If this theory be accepted as feasible, a logical means of treating the condition appears, for we can argue that most of the symptomatology can be related to the raised level of plasma calcium and to the complications known to follow from this. We must stress that when the plasma calcium has been raised for a long time the renal damage may last for some time after the calcium has returned to normal. In such a case the correlation between plasma calcium level and clinical features will not be as close as we observed in the acute observations in our patient. The aim of the treatment must, therefore, be to lower when necessary the plasma calcium to normal levels. One means of achieving this will be to put the infant, as we have done here, on an intake of calcium tolerable without hypercalcaemia and on a diet which is otherwise quite free of vitamin $D$. This has already been reported with hopeful results by Russell and Young (1954), by Ferguson and McGowan (1954) and by Macdonald and Stapleton (1955). We should expect that this treatment would have to be continued for some months to use up stores of vitamin D. After this, the calcium intake can be raised but vitamin $D$ should be given only when it is shown that the child can tolerate ordinary doses. It may be that the addition of calcium-complexing agents to the diet will enable a diet effectively free of calcium to be prepared more easily. We attempted this in a preliminary fashion by adding phytic acid (as 'all-bran') to the diet. However, our evidence is not strong enough for us to conclude that this was effective. Clearly the possibility of the development of rickets must be borne in mind in any child kept on low calcium and low vitamin $\mathrm{D}$ diets for some time, since the calcium balance will be negative during the treatment (Table 2).

Another obvious method of treatment, and one much more easy to realize in practice, is to give cortisone to the infant while it remains insensitive to vitamin $D$. This treatment has been most successful in the hypercalcaemic cases of sarcoidosis 
where the results obtained have suggested strongly that comparatively small doses of cortisone have an anti-vitamin D action (Anderson et al., 1954). It is interesting that cortisone has already been given for a short trial by Creery and Neill (1954) to one infant with idiopathic hypercalcaemia with apparent benefit, and also by Macdonald and Stapleton (1955).

With regard to the nature of vitamin $\mathbf{D}$ intoxication, there has been considerable doubt in the past as to whether pure vitamin D produces toxic symptoms only by virtue of the effects of the hypercalcaemia, or whether some, at least, of the toxicity is due to another action of the vitamin or to other substances present in the vitamin D preparations used. The present study suggests that the intoxication is due mainly at least to the hypercalcaemia, although we have data on other patients indicating that other factors may also be involved and also that the level of hypercalcaemia which produces toxic symptoms varies very greatly from patient to patient. We have known some adults intoxicated with a plasma calcium level of $11 \cdot 5$, while others may be almost symptom-free with a level of 19 . In the same patient, however, the same critical level of toxicity seems to remain fairly constant. If the disease processes in our infant did indeed result from a sensitivity to vitamin $D$, it is clear that in him at least it was mainly the hypercalcaemia which was their immediate cause since all other circumstances were so closely controlled and since repeated alternations of illness and well-being followed changes only of plasma calcium level, induced by changes only in calcium intake.

The main problem remains as to why certain infants may be far more sensitive to vitamin $D$ than others and why they eventually recover spontaneously from this condition. We have no explanation, and can only suggest that the widespread habit of supplementing prepared foods with additional doses of vitamin $\mathrm{D}$ may be dangerous as well as seemingly unnecessary. It is of interest to recall that the same point was made for the same reasons by Thatcher in 1936.

\section{Summary}

A case of idiopathic hypercalcaemia presenting in a boy of 9 months is described.
He was given for 10 days 10,000 units a day of vitamin $D$ by mouth at a time when the disease was in a state of moderate remission. This was followed by an exacerbation of the disease.

His response to a diet alternately containing no calcium at all and then $610 \mathrm{mg}$. per day of calcium (all other factors being constant) was then noted. On the calcium-free diet the plasma calcium level returned quickly to normal and he rapidly improved clinically. On the calcium-containing diet the plasma calcium rapidly rose to abnormal levels and he became ill again. He eventually made a spontaneous recovery and became able to tolerate a normal diet. A two-year follow-up has been maintained during which normal growth and development have been observed.

The clinical and metabolic disorders mimicked closely an intoxication with vitamin D. Presumably the patients with this disease are abnormally sensitive to the vitamin, as most of them appear to have taken only moderate doses.

The theoretical basis of treatment should be a lowcalcium vitamin D-free diet, or else a normal diet taken with cortisone to antagonize the vitamin D in the diet and body stores.

We wish to thank Sister C. Turner and Sister A. Edwards for their nursing care of the patient; Miss D. Tuck for supervising the diets; Drs. J. Anderson and B. Senior for medical assistance; Mr. G. Philpot and Dr. J. Anderson for biochemical assistance, and Mr. V. K. Asta for drawing the figures.

\section{REFERENCES}

Anderson, J., Dent, C. E., Harper, C. and Philpot, G. R. (1954). Lancet, 2, 720.

Bicknell, F. and Prescott, F. (1942). The Vitamins in Medicine, p. 495 . London.

Black, J. A. (1951). Archives of Disease in Childhood, 26, 618.

Clark, E. P. and Collip, J. B. (1925). J. biol. Chem., 63, 461.

Clark, E. P. and Collip, J. B. (1925). J. biol. Chem., 63, 461.

Creery, R. D. G. and Neill, D. W. (1954), Lancer,
Dent, C. E. (1955). Helv. paediat. Acta., 10, 165.

Fanconi, G. and de Chastonay, E. (1950). Ibid., 5, Suppl., p. 5. -_, Girardet, P., Schlesinger, B., Butler, N. and Black, J. (i952). Ibid., 7, 314 .

Ferguson, A. W. and McGowan, G. K. (1954). Lancet, 1, 1272.

Henneman, P. H., Carroll, E. L. and Dempsey, E. F. (1954). J. clin. Invest., 33, 941 .

Lancet leader (1953). Lancet, 1, 78.

Lightwood, R. (1952). Proc. roy. Soc. Med., 45, 401.

, Payne, W. W. and Black, J. A. (1953). Pediatrics, 12, 628. K. G., Henderson, J. L., Park, W. W. and McGreal, D. A. (1954). Lancet, 2, 101.

Macdonald, W. B. and Stapleton, T. (1955). Ibid. In the press. Russell, A. and Young, W. F. (1954). Proc, roy. Soc. Med., 47, 1036. Thatcher, L. (1936). Lancet, 1, 20. 